\title{
ADDICTION, WITHDRAWAL, AND AGGRESSIVENESS IN ADOLESCENCE
}

\section{G. Ungureanu}

\section{Gabriel Ungureanu}

Scientific researcher at the Institute of Philosophy and Psychology "C.R-Motru" within the Romanian Academy.

* Correspondence: Gabriel Ungureanu, Institute of Philosophy and Psychology C.R-Motru, 13 Septembrie Route, No. 13, Bucharest, Romania

E-mail:gabriel.ungureanu.acad@gmail.com

\section{Abstract}

In a tolerant and evasive environment, when the psychological conflict between aspirations and possibilities occurs, naïve, uneducated, and disoriented adolescents often wind up in deviant entourages, surrounded by dubious individuals who promise them the end of "suffering" and the gain of a state of gratification and satisfaction with the help of drug use. Subsequent to these well-intentioned contacts, "white death" drug dealers become violent, demanding very high prices for the "fixes" of this habit. It is the beginning of the end

Key words: addiction; withdrawal; aggressiveness; adolescence; drugs.

\section{Introduction}

The striking gaps of present day society, overhyped without taking corrective measures, the economic elitism of a minority, and the public minimization of young people's self-achievement through work and education have artificially enlarged the category of the socially underprivileged; the romantic optimism typical of the age of adolescence in the time of past generations is nowadays darkened by depression and disengagement. The statistics for high school success rate are always decreasing up to 16-20\% (in the autumn of 2014). The situation is familiar, it is assessed, and linked to the economic state of affairs of the country, but also to the lack of interest or the shocking ignorance of those who are directly concerned: the families of these teenagers. This serious situation impels the youngest members of the society to take refuge in the spirit of groups in which alcohol and drugs are being used.

\section{Drug addiction}

As it is pointed out in the Larousse Dictionary of Psychology, addiction is defined as "a situation of dependence perceived subjectively as alienating, the whole existence of the individual being centered on the repetition of an experience detrimentally to emotional or social investments. The concept of addiction encompasses those of "toxicomany" and "dependence", yet it goes beyond the frame of psychoactive substances dependence to expand to the drug-free toxicomanies or behavioral addictions" (Larousse, 2006, p.25). With respect to the concept of drug one might say it comes from the Persian term droa which translates by "aromatic". According to other sources, it comes from the Hebrew term rakab which means "perfume". The closest to the truth seems to be the Dutch term droog which refers to the vegetal substances sold by pharmacists (Bengescu, 2009). In relation to the phenomenon of withdrawal (the lack of the substance used in addiction), the psychosomatic symptomatology highlights the following types of reactions: 1) psychic: insomnia, anxiety, depression, agitation or excitation; 2) digestive: nausea, regurgitation, stomach aches, anorexia; 3) painrelated: muscle aches, bone pain, visceral pain; 4) neurovegetative: rhinorrhea, ague, sweat (Larousse, 2006, p.1109). 
The psychic profile in the adolescent with addictions is difficult to compile because we can distinguish various social categories among them: marginal, outcasts, mingled, going to school, educated or not and finally drug addicts who come from literally all social structures, large or small. If drug effects are relatively well spelled out, still the individual causes that motivate and lead to drug use are manifold in the neurophysiological spectrum of the "reward" and they are connected to the proper functioning of the systems which comprise: dopaminergic neurons, limbic structures and certain hypothalamic regions (Răşcanu., 2004, p.44). These thinking malfunctions that motivate substance use are highlighted in psychoanalysis, the individual personality traits, as well as in crises.

As a "surface" profile, addiction can be clearly observed: the predisposition to seclude from the community, hanging out at clubs and gardens to contact dealers, significantly diminished school activity, the subject is not interested in ethics, split and inner conflict between the self and personality, ambiguous orientation in terms of goals and values, frequent vengeful feelings against society, perceived as being responsible for their problems.

There is thus a discrepancy between organic maturing and personality development, between the three great modules of psychic calibration: emotional, volitional and cognitive; the adolescent drug addict becomes grumpy and avoids interrogative family discussions; drowsy, visibly tired, with red eyes and dilated pupils; they lie about the groups and locations they frequent and make up financial needs to satisfy urgently; when they can no longer ask for money within the family, they turn to relatives or acquaintances to obtain money or assets which they could sell to get the money they need; given the financial deadlock and being in debt to loan sharks, dealers or even friends, they begin to have antisocial behaviors of violence and theft.

Researchers Molto and Radel, quoted by Vezure (2010), outline an etiological and behavioral diagnosis for the onset motivation of the use of psychedelic, analgesic and stimulating substances: seeking pleasure through an illicit course of action; adherence to groups of drug users; spiritual curiosity; social bluster against adults; social isolation, poverty, lack of perspective on life. Pronounced melancholy and depression are signs of risk based on which measures of prevention against social maladaptation can be initiated.

\section{The classification of illegal drugs and the effects on humans}

Psychoactive substances produce a state of specific consciousness, in a vastly studied succession: sleep, oneiric dynamics, hypnosis, meditation, feedback (Zlate, 2000). The illegal psychoactive substance is defined as "a chemical substance, natural or synthetic, which, unlike medication, acts on the brain, producing euphoric states, psychic disorders, hallucinations, paranoid reactions" (Vezure., 2010, p.13). R.L. Atkinson et al. have come up with the following classification of psychoactive substances in terms of effects: 1) depressive (sedatives): alcohol, barbiturates, tranquilizers; 2) narcotic: opium and its derivatives (codeine, heroin, morphine); 3) stimulating: amphetamine, cocaine, nicotine, caffeine; 4) hallucinogenic or psychedelic: LSD, mescaline; 5) cannabis: marijuana, hashish (Zlate, 2000, p.322). Some drugs are legal: tobacco, alcohol, caffeine, tea and even chocolate (Macovei, 2009). The others are illegal, except for their use in scientific experiments and medicine. According to the degree of dependence which is generated by the use of these substances, the following types of psychosomatic effects are mentioned: psychic, physical and mixed dependence.

Opioids can be classified as follows: natural opioids - opium and opiates; semisynthetic opioids - alkaloids; synthetic opioids e.g. - morphine. Thus, this drug is extracted from the raw seeds of a poppy variety called "Papaverum somniferum". The main derivatives extracted from opium are: heroin, morphine, laudanum, codeine, synthetic derivatives. The psychosomatic effects appear as a state of euphoria, followed by an accentuated exaltation of 


\section{G. Ungureanu}

imagination; during the secondary stage, they produce somnolence and immobility. Through habitualness, the somatic effects become devastating: vertigo, qualmishness, headache, sexual dynamics disorders; they produce physical and psychic dependence with high tolerance. (Ţical.,2003, p.50).

Narcotics: a) heroin (diacetylmorphine) is a morphine synthesized opioid. In terms of effects, intravenous heroin immediately causes an intense reaction of pleasure, euphoria and rush. Then there's a relaxing stage and an intense brain activity of self-searching. This state is called in slang "planet" and it lasts between two and six hours. After repeating heroin administration using the same quantity, the drug addict can no longer get to those intense feelings of pleasure, which is why one calls him "suspended". Given these circumstances, it is highly necessary that the drug quantity be increased in order to obtain the same perceptions. Gradually, a psychosomatic addiction sets in, as well as a degree of tolerance which is irremovable without the help of certified medical assistance. Psychiatric therapy consists of methadone administration in order to sustain psychosomatic balance given the symptoms produced by withdrawal, followed by: individual psychological counseling, psychotherapeutic groups organized in 12 modules, as well as vocational counseling insurance in residential locations vs. on site (Țical, 2003); b) morphine is an opium derivative which is frequently intravenously administered: it acts at CNS level, producing significant pain relief up to total inhibition (by increasing the perception threshold), thus it determines a state of indifference to painful stimuli. Depending on the administered dose, morphine induces a euphoric state followed by a strongly depressing effect, accompanied by convulsions and low blood pressure as a result of veins and arteries dilation. Repeated administration can determine a toxicomany characterized by physical and psychic dependence, but also by the increase of the organism's level of tolerance, which is why it is included in the list of stupefacients (Tical, 2003); c) codeine (methyl-morphine) is a mono-ethylene compound of morphine, a white crystalline solid substance. It is administered either intravenously, or orally, in which case the effect is much weaker, and it also determines a series of adverse effects such as hypoventilation, nausea and regurgitation. The first cases of codeine toxicomany were reported in the US in the '30s, when patients were treated for morphine dependence; d) methadone (diphenyilpropylamine) is a synthesis product with a psycho-clinical activity similar to morphine. It looks like a powder that can be administered orally or intravenously. The effects can last up to 72 hours in some subjects, after a single oral dose. Methadone has all the properties of opioids, causing a sedative, analgesic and anti-cough effect through cerebral activity. Overdose can be deadly, by hypoventilation. Because of the prolonged half-life (it goes up to 25 hours), methadone can be prescribed as a single daily dose. Since it has a relative effect in calming down withdrawal, it is used for the treatment of opioids addictions (Tical, 2003).

Stimulating drugs: a) cocaine is a natural substance extracted from the leaves of coca tree. At present, it is considered illegal, except for medical purposes. It has a stimulating effect similar to that of amphetamines. The effect of body invigoration is general, causing a rapid physical addiction as well. During dose consumption (snorting), the cocaine addict feels a state of wellbeing associated with a delusive feeling of the increase of physical and psychic effort abilities, given the inhibition of sleep need. The euphoric state manifests as absolute happiness and omnipotence, the increase of mobility, disinhibition, the need to communicate and sexual activity. Later on there is a decrease in the quality of thinking, aberrant interpretations of reality, mixed hallucinations, threatening voices materialized in a paranoid medical chart. Finally, given this exhaustion, depression sets in, clinically manifested by indifference and passivity (Tiical, 2003); b) amphetamines are stimulants of the CNS, known for their euphoric effect. They suppress appetite and the state of somnolence, and they combat insomnia. Later on the user becomes irritable, depressed, and lethargic. The repeated use of 
amphetamine produces effects that resemble those produced by cocaine. Similarly, amphetamine addicts need to increase their dose in order to obtain the euphoria effect. They sleep only for a few hours a night and they end up in the psychiatric facility with a state that differs insignificantly from acute psychosis. The addicted user feels threatened and stalked by any stranger around him or her, they have auditory hallucinations and they are completely confused; they feel pains, they present a delirious state and they develop an aggressiveness with paranoid source (Iftene, 2007); c) methamphetamines are synthesis chemical derivatives: for e.g.., Yaba is a stimulating mixture of methamphetamine and caffeine which is found in Southeast Asia. Overdose can become deadly because of the increase of blood pressure and other heart rhythm disorders (Iftene, 2007); d) MDMA or Ecstasy is a stimulating and energizing drug, yet it was never merchandized as medication. It was sometimes administered to the military for its special effects of weariness control; it triggers euphoric stimulation that lasts up to 6 hours, during which weariness disappears and the communication ability increases. The sense of time is lost, light memory disorders appear, and in certain cases, hyperthermia appears; this state is followed by depression and exhaustion, anxiety reactions and the desire to act violently, after which there is a state of somnolence which is accompanied by muscular pains. In the long run, cardiovascular problems occur, as well as renal and hepatic ones (Vartic, 2007); e) AMT/ alpha-Methyltryptamine is a hallucinogenic derivative of tryptamine. It was synthesized in the early '60s in the URSS, being used under the name of INDOPAN.

Hallucinogenic drugs: a) Indian hemp (canabis indica) - is a dicotyledonous herb with a high concentration of THC (tetrahydrocannabinol), the active ingredient. From the resin produced by cannabis hashish is prepared, which is usually smoked. From the flowers and buds of the female cannabis plant marijuana is prepared, often smoked mixed with tobacco. According to the stories of a great number of drug addicts, cannabis preparations induce a state of moderate euphoria which momentarily makes them forget daily problems, increasing the social appetite and ensuring a state of wellbeing. Although It acts on the CNS, cannabis is used in medical issues (Iftene, 2007); b) khat (catha edulis) is a shrub from the leaves of which cathinone is synthesized, an alkaloid that has effects on the organism similar to those of cocaine and amphetamines. Repeated use leads to the settlement of hallucination and paranoia states; c) $L S D$ (lysergide) is a semi-synthetic hallucinogenic drug rated as one of the most powerful known stupefacients. It gives photophobia, physical illness and regurgitation; it produces perceptive changes: geometric shapes that appear eyes closed or open; flashes of intense colors, still objects appear to move, synesthesia (hearing colors). The experiences during LSD exposure are related to individual expectations regarding the use, as well as the suggestions they receive from their social environment. A characteristic of these LSD hallucinations is that the user realizes that what he or she feels and sees is not real. (Iftene, 2007); d) peyote-cactus (Lophophora Wiliamsii)- is a cactus that contains a main alkaloid, mescaline. Those who use preparations from this plant have fantastic visions of greatness or, on the contrary, hilarious ones. These intoxications manifest throughout two to three days, and then they disappear. This drug used to eliminate the state of fear and it gave Native Americans the courage for unequal fight. (Iftene, 2007); e) mescaline was and is still considered a sacred plant. After consumption, it triggers an effect lasting about 12 hours: reactions with neurovegetative symptoms of physical illness, nausea, regurgitation, muscular contractions; an hour after the administration an oneiric state sets in, characterized by the delusion of the visual field and space and time disorientation (Vartic, 2007);

f) hallucinogenic mushrooms psilocybin - is an alkaloid extracted from hallucinogenic mushrooms. The hallucinogenic effect sets in after about 20 minutes and it lasts up to 6 hours, being associated with nausea, muscular contractions and movement lack of coordination; effects of reality distortions and difficulty to orient in space and time (Iftene, 2007); g) $P C P$ - 


\section{G. Ungureanu}

phenyl cyclohexyl-piperidine or Angel Dust acts on the CNS, leading to psychic addiction. Drug addicts who use it frequently manifest a violent behavior: hyperexcitability, irritability, convulsion, depressive-like dysphoria, paranoid states, memory loss, and verbalization difficulties. It can be smoked or administered intravenously (Vartic, 2007); h) volatile substances, such as anesthetics, lacquers (ether), dyes, diluters can have certain depressor and anesthetic effects (Tical, 2010). They are used by marginal groups who can't afford other risk substances in order to induce hallucinogenic states. Given these circumstances, users are disinhibited and they sometimes turn verbally or physically aggressive in relation to the degree of intoxication (Iftene, 2007).

\section{Alcohol addiction (legal drug)}

Alcoholism is a synonym for toxicomany. In both situations the common factor is dependence, but just like in the case of drugs, the drinking onset is psychological. In this regard, personality factors are obvious; first of all, the subjects' volitional, cognitive and emotional mechanisms change within a psychopathological spectrum, presenting as labile, ineffectual structures, and they highlight the difficulty to overcome life hardships in the absence of alcohol. The recourse to alcohol has psycho-sociological connotations marked by "positive" interactions at a group level within the initial phase. During the first phases of the bacchanal behavior people become more sociable, more honest and communicative to one another (In vino veritas! -Latin- in wine there is truth). In our country it is frequent to incite the other to drink alcohol as a tradition: they drink at weddings, but also at funerals, they drink at a newborn's baptism, at various anniversaries, in joy or sorrow, all the same any occasion can bring about the reason for a bacchanal relaxation, individual or in a group. In these situations, the members of the group in most cases become "cheerful" but those who go over the line and become dizzy end up in a state of acute alcohol intoxication or common drunkenness (Ionescu, 1997). Phil et al. quoted by Constanţa Vasile (2009) have confirmed the hypothesis according to which there is a well-determined correlation between the degree of aggressiveness produced through the reduction of inhibitions and the blood alcohol concentration.

Unfortunately, at the level of age consumption, Romanian adolescents come in the first positions in alcohol consumption, $47 \%$ of whom being male subjects, admitting that they have a clear bacchanal experience before the age of 15. A study of the Organization for Economic Co-operation and Development, quoted by Washington Post, highlighted that $18 \%$ of Romanian female adolescents have admitted that they had drunk alcohol at least two times before the time of the interview. Also in this study performed at European level, in the top of alcohol consumption chart come in adolescents from Denmark, Lithuania and Latvia (www.ziare.com). Alcohol consumption in young people and adolescents is an everyday reality that takes mass proportions, in private habitats or in public places, even if merchandizing to persons under 18 is prohibited. Unfortunately, for many adolescents, this behavior leads to the settlement of addiction and chronic alcoholism symptoms, which appear along with all their retinue of specific social malfunctions: job loss, dropping out school, spending personal resources and those of the family on alcohol and, later on, on hospitalization needs (Macovei, 2009).

Vasile Preda argues how the socio-emotional, the ethical, as well as the family's economic climate is more disrupted when in the family there are cases of alcoholism, immorality and criminal record, favoring the children and adolescents' lapse into delinquency by means of a persuasive negative model. Research shows that alcoholism in the families delinquents come from manifest three times more than in the families of non-delinquents. The immorality of the family environment in which alcohol was consumed eventually leads to a permissive atmosphere that favors girls' drinking onset, prostitution, and later on various serious crimes in which they get involved (Preda,1998). 
Clinical manifestations according to George Ionescu (note de curs, 1997) entail two major dimensions of alcohol intoxication: 1) psychopathological manifestations of acute intoxication (common drunkenness) and 2) idiosyncratic alcohol intoxication (pathological drunkenness). If subjects wake up from the first state only with hangover, dizziness and headaches, in the second state of drunkenness (the pathological one) the phenomena are devastating for the individual's health.

Therefore, in certain cases we encounter the occurrence of the withdrawal phenomenon, when the subject cannot administer the alcohol dose from various reasons. These psychic disorders of withdrawal can be found in the following clinical forms: 1) alcohol withdrawal syndrome; 2) alcohol withdrawal delirium; 3) Kandinsky syndrome alcohol amnestic disorder; 4) alcoholic hallucinosis; 5) alcohol related dementia (Ionescu, 1997). However, in adolescence withdrawal and its psychotic symptoms are found seldom, because there must be at least five years before the occurrence of alcohol tolerance and before addiction sets in. The phases of alcoholism onset stretch between three months and two years, and two sub-phases stand out: occasional consumption and continuous consumption. In the second period stretching between six months and four years, in affected subjects one can notice memory loss, the difficulty to describe details, feelings of self-blame and at the same time the ingested quantity of alcohol increases. In the third phase they lose control and they feel the need to drink more and more. The subject is inclined to aggressiveness, low libido up to the point of sexual anesthesia and the annulment of sexual desires. Rationalizations and culpability towards the uncontrollable behavior are produced. Total abstinence without specialized support is attempted and multiple relapses occur that stimulate depressive ideation. Also, a reduction of food appetite is noticed and in most cases social activity (job) is abandoned. In the final phase of chronic alcoholism serious psychopathological phenomena can be distinguished: dipsomania (high level of alcohol consumption within periods of 5 to 6 days) accompanied by violence, hallucinations, and drunkenness during the day, hooliganism and abusive parlance. In this phase, alcohol consumption can take the simple form (with the possibility to abstain) or toxicomany alcoholism (Răşcanu, 2004).

Alcohol use disorder can be described according to ICD (International Classification of Diseases) as having the following dimensions: the alcoholic has a strong desire to drink, he or she cannot control the quantity, the time and place in which they behave that way, the phenomenon of withdrawal occurs when they cannot administer the usual quantity of alcohol. The organism's tolerance to alcohol increases so that it craves for increased doses of alcohol. There's the ignorance of the activities that used to bring them joy as well as the ignorance of destruction caused by alcohol within the organism (Iftene, 2007).

Among the direct consequences which immediately affect alcoholic adolescents we note their positioning as victims or aggressors in situations of violence that are triggered within risk groups. These adolescents experience random sexuality with a high risk of contracting STIs, to which the obvious risk of accidents within the public space is added, because of the difficulty to move given the deficit of orientation in time and space. Social rejection and psycho-moral degradation are obvious, and last but not least, the danger of suicide must be taken into account, lying in wait at every turn because of the internal conflicting states generated at the level of self-esteem, which is getting more and more altered and reduced.

\section{Tobacco addiction (legal drug)}

Tobacco is a plant brought from the US to Europe in the sixteenth century. It is smoked in a pipe, as cigarettes, cigars, cheroots, and sometimes it is chewed. It was noticed that the smoking onset produces around the age of 16, in a social environment, through interinfluence within unsupervised school groups. When one quits smoking, withdrawal produces 


\section{G. Ungureanu}

depression, irritability, frustration or anger, anxiety, difficulties to focus, unrest, and the reduction of cardiac activity. Somatically, a continuous cough reaction occurs, as well the decrease of daily performance. Second, it induces nutritional disorders followed by weight loss or gain. Nicotine contained in tobacco produces "treacherous" addiction effects: statistics show that only $50 \%$ of smokers quit this habit of slow but certain self-ruination of health (Sipos, 2007).

\section{Digital addiction (no substances: computer, Internet, TV)}

Addiction as a phenomenon also refers to other repetitive behavioral manifestations that promote a high level of dependence. Therefore, some adolescents meet the need for interaction by practicing in a group various games of strategy or virtual interaction on the computer. As they wish to gain the acknowledgement of the "online" group, they spend hundreds of hours in front of monitors to gain points and to implement their virtual victories. If manifested excessively, this behavior leads to physical and mental exhaustion often causing serious illnesses and psychosomatic conditions.

Watching television or looking at aggressive or cruel images on the computer sometimes triggers unconscious curiosity, being actually preferred by some frustrated adolescents. Computer games with fights or war strategies are also accessed by many pupils, and these activities hold an important position in the formation of their thinking.

As it is statistically assessed, before the age of 16, the child can watch 13.000 murders and aggressive attacks on television. Scientific inquiries targeting the influence of aggressogenic films on the adolescents' manifest behavior have shown that some of them appropriate scenes from films per se, without making the distinction between pro-social aggressiveness and the antisocial one, being mainly interested in the assault techniques which they learn spontaneously (Preda, 1998).

Studying the emotional correlation with dependence as to video games and comparing them to the indicators of emotional dependence as to gambling, D. A. Gentile and J.R. Gentile have come to the conclusion that $15 \%$ of the studied adolescent gamblers are addicted. Research showed that dependence is significantly correlated to the emotional feedback of aggressive video games, hostility and fights that start in the close environment (Tarasov, p.63).

Attempting to regulate this social issue, as early as 1993 the classification of video games was asserted as follows: "E (everyone) for anyone, $\mathrm{T}$ (teen) young people, and $\mathrm{M}$ mature; this aspect led to the limitation of children's access to games that were not appropriate to their age.

Thus, in 2003 Entertainment Software Rating Board presented an improved classification starting with the age of three, up to adults over 18. Although research in the scope of this phenomenon is scarce, one can still state that policies formulated as a result of scientific salience have significantly reduced the rate of dependence behaviors (Tarasov, p.64).

Other adolescents are emotional and they cannot communicate to one another unless they are behind the relative anonymousness ensured by the chat or email relationship. This technology first appears as being salutary for these children who can thus interact easier; but there are many counterexamples that prove the contrary with respect to the usefulness of Internet, since many adolescents in pursuit of pleasure and easily made money collapse into promiscuity and online prostitution dependence, bringing illicit revenue.

\section{Conclusions}


It is interesting that in this scope of addictions, drug addicts do not crave to change their addiction and they become for instance workaholics. Neither are those who buy compulsively (shopaholics) drawn to the adherence to dependence altruistic behavior.

Being aware that they are different "ideologically", with a "bluster" attitude towards the large majority of people, each of these persons who are temporarily deviated from normality maintain their philosophical-attitudinal typicality, but also their behavioral manifest towards other people and towards society, even if sometimes they practice and even provoke co-dependence in addictions. It seems that these people are searching for an intense hedonistic compensation for their inability to find solutions to life challenges.

Addiction behavior with no substances is no less harmful, through the negative processing of cognitive-emotional sets of adolescents who waste their time on public games in bars or at home in front of the computer, ending up most often ruined and stuck with debts. Inveterate gamblers of casinos are recruited among them. Most of them end up being socially excluded, in debt for life to banks and loan sharks. Frequently, these teenagers without a "compass" become depressed, out-of-balance, they have suicidal thoughts which unfortunately many times they bring off (Joiner, 2013).

\section{Bibliography:}

1. IONESCU G., (1997) Tulburarea personalităţii Editura Asklepios, Bucureşti, p. 80-167;

2. IONESCU G., (1997). Note de curs;

3. PREDA, V., (1998). Delicvenţa juvenilă. Cluj-Napoca, Presa Universitară Clujeană;

4. ZLATE, MIELU., (2000) Introducere în psihologie. Editura Polirom, Iaşi;

5. ȚICAL, GEORGE, M., (2003) Manual antidrog: Prevenirea şi combaterea traficului şi consumului de droguri:Elemente de indentificare şi efectele drogurilor: Curs universitar. Editura Pildner \& Pilner, Târgoviște;

6. RĂŞCANU, RUXANDRA., (2004) Alcool şi droguri. Virtuţi şi capcane pentru tineri Editura Universităţii din Bucureşti;

7. TARASOV, A., (2006) Psihologia jocurilor video. Agresivitatea şi sugestibilitatea la adolescenţii expuşi jocurilor video violente. Iaşi, Editura Lumen;

8. BLOCH, H., ROLAND, C., ERIC, D., ALAIN,G., (2006) Larousse- Marele dicţionar al psihologiei. Bucureşti, Editura Trei;

9. EFTENE, FELICIA., (2007) Comportamente adictive ale copiilor şi adolescenţilor. Ghid pentru medicul de familie. Editura Alma Mater, Cluj-Napoca;

10. CHIPEA, FLOARE., STANCIU, SIMONA., (2007) Tinerii şi drogurile. Dimensiuni psihosociale şi politici de prevenire a consumului de droguri Editura Universităţii din Oradea.

11. BENGESCU-BELLU, C., (2009) Ghidul voluntarului antidrog care acţionează pentru prevenirea şi reducerea consumului de droguri în şcoli Editura Universitară Bucureşti, p. 14.

12. MACOVEI, R, A., (2009) Toxicodependența. Impact social. Aspecte medicale. Consecințe juridice. Editura PrinTech;

13. VEZURE, DANA, EUGENIA., (2010) Toxicomania în şcoală. Specific şi modalităţi de prevenire. Editura Sitech. Craiova;

14. JOINER, T., (2013) Mituri despre sinucidere Editura trei, Bucureşti.

\section{Webliography}

www.ziare.com/articole/statistici+consum+alcool

www.despresuflet.ro. Constanţa Vasile, Factori determinanţi în creşterea nivelului de agresivitate. Influenţa drogurilor asupra agresivităţii. 